\title{
Gestão de Custos no Setor Governamental: Experiência numa Secretaria Municipal de Educação
}

\author{
Antonio Lopo Martinez \\ Professor da Fucape Business School \\ Av. Fernando Ferrari, 1358. Boa Vista. Vitória/ES. CEP: 29075-505 \\ E-mail: lopo@fucape.br
}

\section{RESUMO}

Este artigo discorre sobre o desenvolvimento de um modelo conceitual de custos para o Setor Público. O caso concreto analisado é o da Secretaria Municipal de Educação de Salvador (SMEC/SSA). A Lei de Responsabilidade Fiscal, particularmente o art. 50, §3ㄴ, prescreve a necessidade do controle de custos no setor público, demandando por conseqüência a busca de soluções compatíveis para a área pública. A partir de estudos e pesquisas in loco, este trabalho apresenta e discute uma solução proposta para a SMEC/SSA. A despeito de peculiaridades no modus operandi da área pública, notadamente a flutuante cultura organizacional, procurou-se identificar as premissas mais relevantes para montagem de um sistema de acumulação de custos, chegando ao custo por escola e custo por aluno. A construção desse sistema de custos buscou atender às necessidades de avaliação, acompanhamento e controle da gestão orçamentária, financeira e patrimonial. Foi priorizado o desenvolvimento de um modelo geral e flexível, que possa ser aperfeiçoado gradativamente de acordo com a evolução da dinâmica cultural, organizacional e tecnológica do ente público.

Palavras-chave: Sistema de custos. Contabilidade governamental. Controle de custos.

\section{Cost Management in Government: A View into the Municipal Department of Education}

\section{ABSTRACT}

This paper discusses the development of a conceptual cost model for the Public Sector. The case analyzed is the Municipal Department of Education in Salvador (SMEC / SSA). The Fiscal Responsibility Law, particularly art. 50, $\S 3$, prescribes the need for cost control in the public sector demanding as consequence the search for compatible solutions for the public area. From studies and research in loco, this paper presents and discusses a proposed solution to the SMEC / SSA. Despite the peculiarities in the modus operandi of the public area, especially the floating organizational culture, we sought to identify the most important premises for setting up a system of accumulation of costs, even to the cost per school and cost per pupil. The construction cost of the system tried to address the needs assessment, monitoring and control of budgetary, 
financial and real estate. Was prioritized the development of a general and flexible model that can be improved gradually in accordance with the development of cultural dynamics, organizational and technological public entity.

Keywords: Cost system. Government accounting. Cost control.

\section{INTRODUÇÃO}

Qual a real utilidade de um sistema de gestão de custos no setor público? Em que medida tal instrumento irá atender aos interesses dos poderes executivos que se sucedem? Os atuais procedimentos legais de evidenciação das contas públicas propiciam mais transparência e mais controle de gastos, visando refletir eficiência e eficácia dos programas de governo? As possíveis respostas a essas questões geralmente têm servido como restrições à implantação de sistemas de custos e à avaliação do desempenho econômico e financeiro nessas entidades.

Este trabalho não se propõe a trazer soluções para essas questões, mas visa propiciar uma contribuição para pelo menos três aspectos: a) apresentar um instrumento consistente que possa contribuir no aumento da transparência na gestão da coisa pública, restringindo seus gestores a agirem conforme os ditames e princípios da administração pública; b) apresentar mais um referencial concreto do desenvolvimento de um sistema de custos no setor público; e c) mostrar que o uso efetivo e sistemático deste tipo de instrumento poderá concretamente contribuir para melhoria da gestão orçamentária, financeira e patrimonial de uma entidade pública nos aspectos de eficiência e economicidade.

A busca das organizações governamentais por profissionalização, eficiência e efetividade vêm, cada vez mais, se configurando como uma prioridade. Através da implantação de instrumentos de mensuração que permitam um monitoramento sistemático de seu desempenho econômico e financeiro, estas entidades podem dar um grande salto de qualidade no que vem se denominando de "Nova Gestão Pública" e Governança. 
Neste sentido, algumas ações têm sido colocadas em prática, tais como a Lei de Responsabilidade Fiscal (LC n¹01/2000) que, em seu art. 50, parágrafo $3^{\circ}$, dispõe: "A administração pública manterá sistema de custos que permita a avaliação e o acompanhamento da gestão orçamentária, financeira e patrimonial".

Com um sistema de custos, o processo de avaliação de desempenho da gestão pública poderia ser melhorado através da monitoração de informações e indicadores, dos vetores ligados a efetividade em relação ao alcance das metas planejadas, qualidade dos serviços, processos e economicidade, que corresponde ao padrão de custos no alcance destas metas.

Através da análise de um caso real, são apresentados os principais aspectos, fundamentos e procedimentos necessários ao desenvolvimento e adequação de um sistema de custos para a área pública, em particular a Secretaria Municipal de Educação de Salvador (SMEC/SSA). O caso mostra como os custos foram acumulados até se chegar ao custo por escola e o custo por aluno. O que se pretende destacar é a importância administrativa desse instrumento, que pode estimular e ampliar as possibilidades do gestor público na condução econômica e financeira do patrimônio público, principalmente através da otimização da função controle.

O trabalho enfatiza a importância da implantação de sistema de custos no setor público, destacando, também, as principais restrições a essa implantação. Através do estudo de caso real, são descritas e analisadas as etapas para o desenvolvimento do sistema de custos na SMEC e apresentados os principais resultados e conclusões obtidas.

\section{ADMINISTRAÇÃO PÚBLICA: ACCOUNTABILITY E GESTÃO DE CUSTOS}

Segundo Meirelles (2009, p.86), "os fins da administração pública resumem-se num único objetivo: o bem comum da coletividade administrada". Quando o administrador público se afasta ou se desvia deste objetivo, ele trai o mandato para o qual foi investido. Percebe-se neste contexto a gravidade do dever de prestar contas (accountability) à sociedade. E esse dever é efetuado através do auxílio principalmente 
de informações contábeis, em conformidade com os dispositivos legais em vigor relativos à contabilidade pública.

Apesar dos mandamentos legais, ainda são muitos os casos de entidades públicas que têm suas prestações de contas desaprovadas pelos Tribunais de Contas. Estes indicativos apontam para pelo menos três hipóteses: a) alguns extratos da sociedade e/ou órgãos representativos não são muito exigentes em cobrar qualidade e rigor na prestação de contas dos gestores públicos; b) a elaboração e apresentação das informações por algumas entidades ainda são preparadas sem o devido rigor e sem o acompanhamento de uma auditoria interna; c) a elaboração e evidenciação dos informes contábeis ainda é limitada, permitindo a apresentação de informações segundo a conveniência do poder executivo.

Uma das principais características de um sistema de gestão de custos (SGC) é a sua utilidade na função administrativa ou gerencial, ou seja, o seu uso de caráter interno pelos gestores. Esse uso sistemático poderá aumentar a qualidade das informações quando da elaboração anual das prestações de contas. Uma vez que este tipo de sistema utiliza informações físicas e monetárias, estas permitirão ainda a comparação de valores reais com os planejados, contidos nos instrumentos de planejamento (Plano Plurianual - PPA, Lei de Diretrizes Orçamentárias - LDO e a Lei Orçamentária Anual - LOA) permitindo planejar melhor e de forma mais detalhada os seus gastos mensais em projetos e atividades.

Além do disposto anteriormente, os gestores teriam uma maior flexibilidade e até alguma informalidade para elaboração de relatórios com indicadores-chave de desempenho, favorecendo o controle das diversas operações e atividades das entidades. Enfim, um sistema de gestão de custos propiciaria inúmeros benefícios para o setor público. De um lado, poderia ampliar a avaliação de seu desempenho econômico, financeiro e patrimonial, de outro, poderia otimizar a função controle na tentativa de tornar mais transparentes a comunicação de seus relatórios, resultantes de suas gestões em contraste com os seus programas de governo. 


\section{GESTÃo DE CUSTOS E SISTEMAS DE GESTÃo DE CUSTOS (SGC)}

O modelo conceitual do sistema de gestão de custos da Secretaria Municipal de Educação foi desenvolvido a partir de uma concepção sistêmica da contabilidade de custos aplicada à SMEC, vista na figura a seguir. O objetivo central foi se chegar aos custos por escola e custo por aluno.

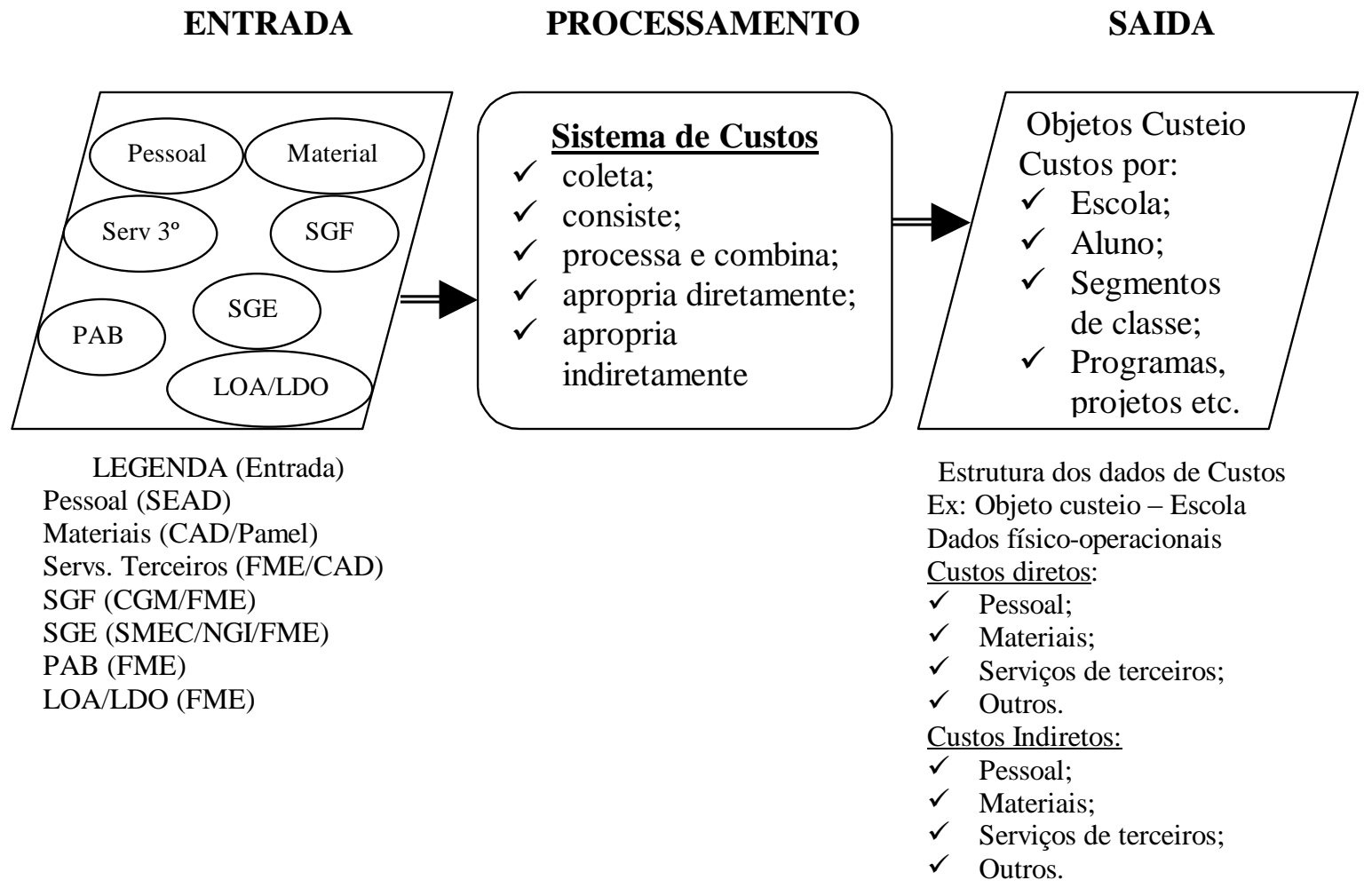

Figura 1 - A Contabilidade de Custos numa abordagem sistêmica aplicada à Secretaria Municipal de Educação de Salvador - SMEC/SSA (adaptado pelos autores)

\subsection{O que poderia ser um sistema de gestão de custos (SGC) para a área pública?}

Martins (2003) entende que a escolha do sistema está condicionada ao objetivo que se pretende atingir. O mesmo ocorre com o seu detalhamento e do quanto deverá ser despendido para a sua obtenção. O autor assinala que as informações são caras e 
sua utilidade não é igual em todos os níveis de detalhes, tornando temerária a sua adoção como pacote.

Os legisladores ainda não regulamentaram o que se entende como um sistema de custos no setor público. Este aspecto pode servir de justificativa para que, entre outras coisas:

a) Os contadores ou profissionais especialistas na área possam desenvolver os modelos conceituais dos sistemas de custos baseados na fundamentação teórico-doutrinária existente;

b) Os gestores possam gerir os seus projetos e atividades estabelecidos nos instrumentos de planejamento (LOA / LDO, PPA) de forma mais eficiente e eficaz, detalhando o período de competência anual dos exercícios para bases mensais, respaldado no Princípio da Competência;

c) Os gestores possam ainda utilizar custos pré-estabelecidos ou padrões mensais com base na LDO ou equivalente, para auxiliar na elaboração do orçamento e ainda determinar os seus resultados prévios, antecipando-se ao "fechamento" periódico da Contabilidade Pública, e

d) Se possa otimizar os processos de avaliação de desempenho, controle e de tomada de decisões, agindo mais intensamente durante o exercício fiscal e não após ou ao final dele.

Para melhor fundamentar as características que um sistema de gestão de custos (SGC) deve possuir no setor público, foram sintetizados alguns de seus objetivos em contraste com algumas óticas de cultura organizacional pública:

\begin{tabular}{|c|c|c|c|}
\hline $\begin{array}{c}\text { Objetivos da gestão } \\
\text { de custos }\end{array}$ & Gerencialismo puro & Consumerismo & $\begin{array}{c}\text { Administração voltada } \\
\text { para o cidadão }\end{array}$ \\
\hline $\begin{array}{c}\text { Análise, } \\
\text { planejamento e } \\
\text { controle }\end{array}$ & $\begin{array}{c}\text { Foco no curto prazo e } \\
\text { equilíbrio fiscal. }\end{array}$ & $\begin{array}{c}\text { Foco na qualidade do } \\
\text { gasto público. }\end{array}$ & $\begin{array}{c}\text { Foco na qualidade do } \\
\text { gasto e observância das } \\
\text { demandas do cidadão. }\end{array}$ \\
\hline Processo decisório & $\begin{array}{c}\text { Não utilização de } \\
\text { sistemas de custos }\end{array}$ & $\begin{array}{c}\text { Utilização de conceitos } \\
\text { de sistemas de custos }\end{array}$ & $\begin{array}{c}\text { Utilização de conceitos de } \\
\text { sistemas de custos }\end{array}$ \\
\hline Desempenho & Corte de gastos & Foco no valor & Foco em valor \\
\hline
\end{tabular}

Quadro 1 - Objetivos da gestão de custos versus filosofia da gestão pública gerencial. 
Observa-se uma tendência crescente, no setor público, de se aderir a princípios e padrões modernos de gestão condizentes, entre eles o Total Quality Management (TQM), fazendo-se uma analogia do cidadão com o cliente.

Para a implantação bem-sucedida de um sistema de gestão de custos no setor público, é necessário observar alguns elementos importantes que podem servir de guia:

- Apesar de previsto na Lei de Responsabilidade Fiscal, não há legislação ordinária que obrigue a existência de sistemas de custos no setor público. Também não existem ainda experiências robustas de sucesso de implantação;

- Os atuais sistemas contábeis e financeiros existentes na administração pública, tais como contabilidade e orçamento, foram desenvolvidos na égide da administração burocrática não contribuindo de forma efetiva para as novas demandas sociais (são auto-referentes, formalistas e fiscalistas);

- Os sistemas de custeio devem estar integrados às realidades operacionais, organizacionais e físicas da entidade;

- Os diversos sistemas de informação existentes servirão de alimentação de dados primários para a gestão de custos;

- Deve-se iniciar o processo de gestão de custos com sistemas mais simples, mesmo com limitações, pois o setor público não possui ainda o padrão de aprendizagem necessária para a utilização de sistemas de custeio mais complexos e de alto custo de implantação como é o caso do custeio baseado em atividades ( $A B C)$;

- A implantação de sistemas de custos no setor público requer uma abordagem inter e multidisciplinar, abrangendo questões relativas à teoria mais atual sobre administração pública, ciência política, teoria de sistemas e organizações;

- A moderna gestão de custos pode ser situada teoricamente no instrumental analítico da nova gestão pública; 
- As especificidades do setor público requerem a observância de fatores políticos, institucionais e culturais.

Costa (1998, p. 67-77) observa que um sistema de contabilidade de custos deve

(...) envolver um conjunto de princípios e procedimentos relacionados à observação, análise, registro, interpretação e relato dos fenômenos relacionados ao objeto da contabilidade de custos, e suas causas, de forma que o usuário das demonstrações contábeis interessado naqueles fenômenos faça utilização das informações geradas pelo sistema no seu processo decisorial.

A dinâmica do processo decisório impõe ao gestor que sejam utilizados na gestão do dia-a-dia mais dados presentes e futuros do que dados passados e a combinar dados físicos com dados monetários. Esses aspectos tornam os sistemas de gestão de custos muito úteis, porquanto não dependem, necessariamente, da contabilidade "fechar" seu movimento para se saber qual foi o custo das operações do período.

Essa peculiaridade gerencial propicia que um sistema de custos possa perfeitamente trabalhar com dados estimados e pré-estabelecidos. Para tanto, faz-se necessário a utilização de técnicas auxiliares e, sobretudo, lógica, racionalidade, relevância e bom senso. Contudo, mesmo agindo com rigor na elaboração das estimativas, é necessário que as informações levantadas sejam ajustadas, cumulativa e periodicamente, visando a sua compatibilização com os dados reais da contabilidade.

Junto com os objetivos, outro aspecto que deve ser ressaltado em um sistema de custos é a sua customização, ou seja, o modelo conceitual deve ser desenvolvido caso a caso, segundo a peculiaridade da entidade e de acordo com as necessidades da gerência (ROEHL-ANDERSON; BRAGG, 2008).

Entre os inúmeros benefícios que a implantação e o uso contínuo de sistemas de custos propiciariam para o setor público e para a própria sociedade, poderiam ser destacados: 
a) O aperfeiçoamento da apreensão (captura) e delimitação dos valores que contribuirão para o desenvolvimento dos diversos processos e atividades, resultando nos custos dos vários serviços públicos disponibilizados;

b) O dimensionamento ou redimensionamento dos preços dos serviços públicos com maior transparência e objetividade, pela identificação dos seus custos reais (ou quase reais);

c) O controle da economicidade das operações. $O$ uso de um adequado planejamento e acompanhamento das atividades, avaliando a eficácia das operações, propiciará subsídio ao processo de tomada de decisões, com um efetivo controle de custos, redução de desperdícios, entre outros;

d) A melhoria do processo de planejamento. Com o detalhamento dos custos por centro de custos e a determinação dos custos totais de cada serviço disponibilizado, o orçamento seria muito melhor utilizado;

e) O dimensionamento e redução da capacidade ociosa, através da identificação da capacidade total e do grau de utilização desta pelo órgão ou unidade analisado;

f) A conseqüente racionalização dos custos, otimizando a aplicação dos recursos públicos;

g) A avaliação, simulação e análise de alternativas, visando otimizar os processos e atividades de elaboração dos serviços públicos.

\subsection{Qual o método de custeio a ser adotado?}

Conforme observado anteriormente, a necessidade das informações pelo usuário definirá o modelo. O levantamento da realidade físico-operacional da entidade, com seus processos e atividades, também implicará na definição do tipo de método de custeamento. $\mathrm{O}$

Quadro 2 a seguir procura ilustrar esse aspecto comparando três métodos. 


\begin{tabular}{|c|c|c|c|}
\hline Critério & Vantagens & Desvantagens & $\begin{array}{c}\text { Observações e } \\
\text { Sugestões }\end{array}$ \\
\hline $\begin{array}{c}\text { CUSTEIO } \\
\text { POR } \\
\text { ABSORÇÃO }\end{array}$ & $\begin{array}{c}\text { Simplicidade; } \\
\text { Custo / benefício; } \\
\text { Base no Princípio da } \\
\text { Competência; } \\
\text { Adequado à área pública } \\
\text { em função do tratamento } \\
\text { dos custos fixos, que são } \\
\text { preponderantemente de } \\
\text { longo prazo; } \\
\text { Segregando os gastos em } \\
\text { relação ao seu objeto, } \\
\text { poder-se-ia contemplar, } \\
\text { em parte, a visão } \\
\text { gerencial propiciada pelo } \\
\text { custeio variável. }\end{array}$ & $\begin{array}{l}\text { Rateio arbitrário dos custos } \\
\text { indiretos e fixos; } \\
\text { Precisão não muito acurada } \\
\text { (qualidade da informação) }\end{array}$ & $\begin{array}{l}\text { Sofisticar e refinar os } \\
\text { critérios de rateio, } \\
\text { fundamentando-os } \\
\text { metodologicamente; } \\
\text { Ponto crítico para } \\
\text { questionamento pela } \\
\text { comunidade acadêmica; } \\
\text { Encontrar formas de } \\
\text { reduzir viés no rateio, } \\
\text { usando: } \\
\text { departamentalização, } \\
\text { homogeneização dos } \\
\text { centros de gastos, bem } \\
\text { como avaliação acurada } \\
\text { dos direcionadores de } \\
\text { custos; } \\
\text { Avaliar tratamento a ser } \\
\text { dado à ociosidade. }\end{array}$ \\
\hline $\begin{array}{l}\text { CUSTEIO } \\
\text { VARIÁVEL }\end{array}$ & $\begin{array}{l}\text { Importância e utilidade do } \\
\text { conceito de margem de } \\
\text { contribuição } \\
\text { Inexistência de rateio de } \\
\text { custos; } \\
\text { Fácil aplicação; } \\
\text { Custo / benefício. }\end{array}$ & $\begin{array}{c}\text { Dicotomia curto versus } \\
\text { longo prazo, com ênfase no } \\
\text { curto prazo; } \\
\text { Relevância dos custos } \\
\text { indiretos sobre os diretos. }\end{array}$ & $\begin{array}{l}\text { Não aplicabilidade do } \\
\text { conceito de margem de } \\
\text { contribuição no setor } \\
\text { público. }\end{array}$ \\
\hline $\begin{array}{l}\text { CUSTEIO } \\
\text { ABC (Custeio } \\
\text { baseado em } \\
\text { atividades) }\end{array}$ & $\begin{array}{c}\text { Maior acurácia e, por } \\
\text { conseqüência, maior } \\
\text { qualidade nas } \\
\text { informações de custos de } \\
\text { processos e de serviços; } \\
\text { Flexibilidade; } \\
\text { Maior sofisticação no } \\
\text { tratamento dos custos } \\
\text { indiretos, que são } \\
\text { preponderantes na área } \\
\text { pública. }\end{array}$ & $\begin{array}{c}\text { Muito oneroso; } \\
\text { Prazo muito longo para } \\
\text { implementação e } \\
\text { maturação; } \\
\text { Muito complexo no } \\
\text { mapeamento dos processos } \\
\text { e atividades e, por } \\
\text { conseqüência, na } \\
\text { identificação e apropriação } \\
\text { dos custos pelos objetos de } \\
\text { custeio. }\end{array}$ & $\begin{array}{l}\text { Risco elevado ao migrar } \\
\text { para um estágio } \\
\text { relativamente avançado em } \\
\text { sistema de controle } \\
\text { gerencial, sem ter tido a } \\
\text { experimentação e o } \\
\text { aprendizado de um estágio } \\
\text { anterior. }\end{array}$ \\
\hline
\end{tabular}

Quadro 2 - Análise comparativa de metodologias de custeamento, sob a ótica de cultura e contexto organizacional do Setor Público

Pode-se perceber que o custeio por absorção, desde que seja usada a técnica de departamentalização de forma concomitante, é a metodologia mais adequada, sobretudo quando um dos principais objetivos da implantação é a sua eficácia. Ou seja, num primeiro estágio é deveras importante que exista um sistema de custos funcionando regularmente, mesmo com algumas limitações. Num segundo estágio, já com alguma massa crítica, poderiam ser efetuados alguns aperfeiçoamentos e 
promover a migração para uma versão primária do modelo $A B C$. Num terceiro estágio, então, poderia ser efetuada a migração plena e mais detalhada para o modelo escolhido, no caso o custeio ABC.

A principal limitação ou cuidado para utilização imediata do custeio $A B C$ é que este exige um trabalho maior no desenvolvimento, desde a definição das diversas atividades e direcionadores de custos, exigindo um maior rigor e formalismo nos sistemas de controles internos necessários para viabilizar esta metodologia até a implantação propriamente dita, que exigiria mais recursos humanos e materiais.

\subsection{Restrições para a implantação de um sistema de gestão de custos no setor público}

Embora haja inúmeros benefícios que um sistema de custos proporcionaria para o setor público, existem algumas restrições importantes que devem ser destacadas, conforme quadro e descrição a seguir:

\begin{tabular}{|c|c|}
\hline FATORES & MOTIVAÇÕES \\
\hline CULTURAIS & $\begin{array}{c}\text { Inexistência de cultura de avaliação de custos e desempenho no } \\
\text { setor público. Cultura formalista, auto-referente e burocrática. }\end{array}$ \\
\hline POLÍTICOS & $\begin{array}{c}\text { Muitas vezes os políticos não estão interessados em avaliação de } \\
\text { seu próprio desempenho gerencial. O horizonte de preocupação } \\
\text { limita-se ao seu mandato. }\end{array}$ \\
\hline TÉCNICOS E OPERACIONAIS & $\begin{array}{c}\text { Os sistemas contábeis e gerenciais atualmente existentes não se } \\
\text { adeqüam a elaboração de sistemas de custos e desempenho. } \\
\text { Além disto, a qualidade das informações produzidas não é } \\
\text { adequada, dado o grande número de vieses e ruídos produzidos. }\end{array}$ \\
\hline INSTITUCIONAIS & $\begin{array}{c}\text { Os diversos instrumentos de gestão pública institucionalizados no } \\
\text { Brasil, principalmente os relativos a aspectos financeiros, não } \\
\text { apresentam um direcionamento efetivo para a avaliação de } \\
\text { desempenho. }\end{array}$ \\
\hline
\end{tabular}

Quadro 3 - Barreiras à implantação de sistemas de gestão de custos no setor público

\section{O CASO - SGC SMEC/SSA/BA}

O caso a seguir foi desenvolvido na Secretaria Municipal de Educação e Cultura de Salvador, Bahia (SMEC/SSA). Dentre as cerca de 360 escolas existentes na época do levantamento de campo, foram escolhidas três escolas: Amélia Rodrigues, Helena 
Magalhães e Teodoro Sampaio. Estas escolas pertencem respectivamente às Coordenadorias Regionais (CRE's) do Centro, São Caetano e Orla, que representam as regiões administrativas de Salvador, que são em número de 11 (onze).

A SMEC/SSA foi criada pela Lei o․ 912, de 04 de março de 1959 e reorganizada por leis posteriores, tendo como finalidade central desempenhar as funções do município em matéria de educação e cultura. Possui natureza jurídica de administração direta em relação à Prefeitura Municipal de Salvador, sendo responsável por definir políticas, metas e procedimentos em relação ao serviço de educação e cultura da cidade. Em relação aos seus aspectos operacionais, a SMEC/SSA é responsável por desenvolver as seguintes atividades:

- Organização e administração do sistema municipal de ensino;

- Elaboração, execução e controle do Plano Municipal de Educação - PME;

- Promoção, orientação, coordenação e supervisão das atividades didáticopedagógicas;

- Administração do programa de capacitação dos profissionais de educação;

- Articulação com outros órgãos ou instituições públicas e privadas, nacionais e internacionais com vistas ao cumprimento de suas finalidades.

\subsection{Descrição do modelo conceitual básico do SGC na SMEC}

O modelo conceitual do SGC da SMEC foi desenvolvido para contemplar as atividades de educação para tender todas as escolas existentes ou que venham a ser criadas ou municipalizadas. Foram usadas três escolas, adotadas como amostra. No levantamento de campo foram identificados os principais processos e atividades operacionais e administrativas de todos os centros de custos constantes do organograma oficial (sintetizado na Figura 2). 


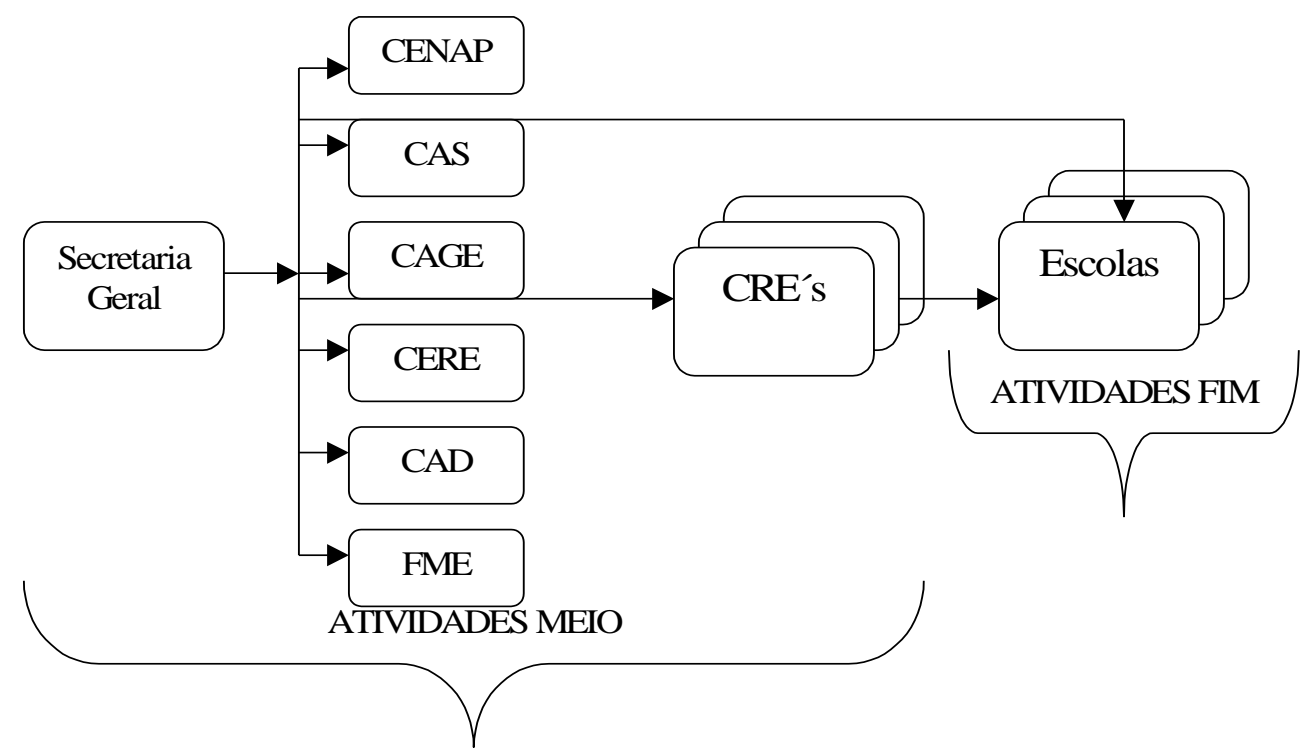

Figura 2 Estrutura Simplificada do Organograma da SMEC/SSA

Secretaria Geral: Gabinete do Secretário CENAP: Coord. de Ensino e Apoio Pedagógico CAS: Coordenadoria de Ações Sócio-educativas CAGE: Coord.Apoio e Gerenciamento Escolar
Legenda:

CERE: Coord. Estrut. Rede Física Escolar

CAD: Coordenadoria Administrativa

FME: Fundo Municipal de Educação

CRE's: Coordenadorias Regionais

Adotou-se ainda o mês de março como referência para análise mensal, tendo em vista ser um período de atividades normais de ensino. Após o diagnóstico inicial para elaboração do plano de intervenção, foram verificados alguns aspectos limitantes para desenvolvimento do SGC, tais como:

i. A contabilidade da SMEC não estava estruturada por centros de custos;

ii. O sistema de controle interno ainda não estava preparado para permitir o desenvolvimento de um sistema de custos;

iii. Não havia na ocasião, qualquer sistemática interna de apuração e relato de custos para fins gerenciais.

Com base nestas informações e no prazo para execução dos trabalhos, foram definidos alguns objetivos fundamentais norteadores para se implantar uma estrutura básica do SGC:

a) Desenvolver um modelo conceitual básico de custos que contemplasse as mais relevantes operações e atividades da entidade; 
b) Verificar a regularidade de seu funcionamento, através da observação, análise e controle das informações obtidas;

c) Incorporar as demais operações e atividades não contempladas no item (a) e detalhá-las conforme a necessidade dos usuários finais das informações;

d) Incorporar, gradativamente, melhorias e rotinas complementares que se fizerem necessárias, inclusive com a alteração de métodos e/ou técnicas de custeio.

Para a consecução dos objetivos mencionados anteriormente, foram delineados alguns caminhos e estratégias para obtenção e tratamentos dos dados:

- Definir os objetos de custeio (custos por escola, custos por aluno etc.);

- Fazer um levantamento minucioso dos dados constantes dos sistemas que integravam a contabilidade da SMEC (pessoal, materiais, serviços de terceiros e outros), buscando identificar, relacionar e definir os elementos de despesa pelos departamentos (centros de custos) constantes do organograma regimental;

- Correlacionar os dados da execução orçamentária com as informações constantes nos instrumentos de planejamento (Lei Orçamentária Anual - LOA, Lei de Diretrizes Orçamentárias - LDO e Plano Pluri-Anual - PPA);

- Coletar dados físicos e operacionais relativos às atividades fins da SMEC (quantidades de alunos e professores por escolas, tipos de séries etc.);

- Após determinar os custos por centros de custos (departamentos), definir regras e atributos (relações de causa e efeito) que permitissem a transferência dos custos dos setores administrativos para os objetos de custeio finais (escolas e alunos).

Através do levantamento de campo nas escolas e nas coordenadorias operacionais foram identificadas as principais atividades específicas desenvolvidas numa unidade escolar, sintetizadas de forma esquemática na Figura 3 , a seguir. 


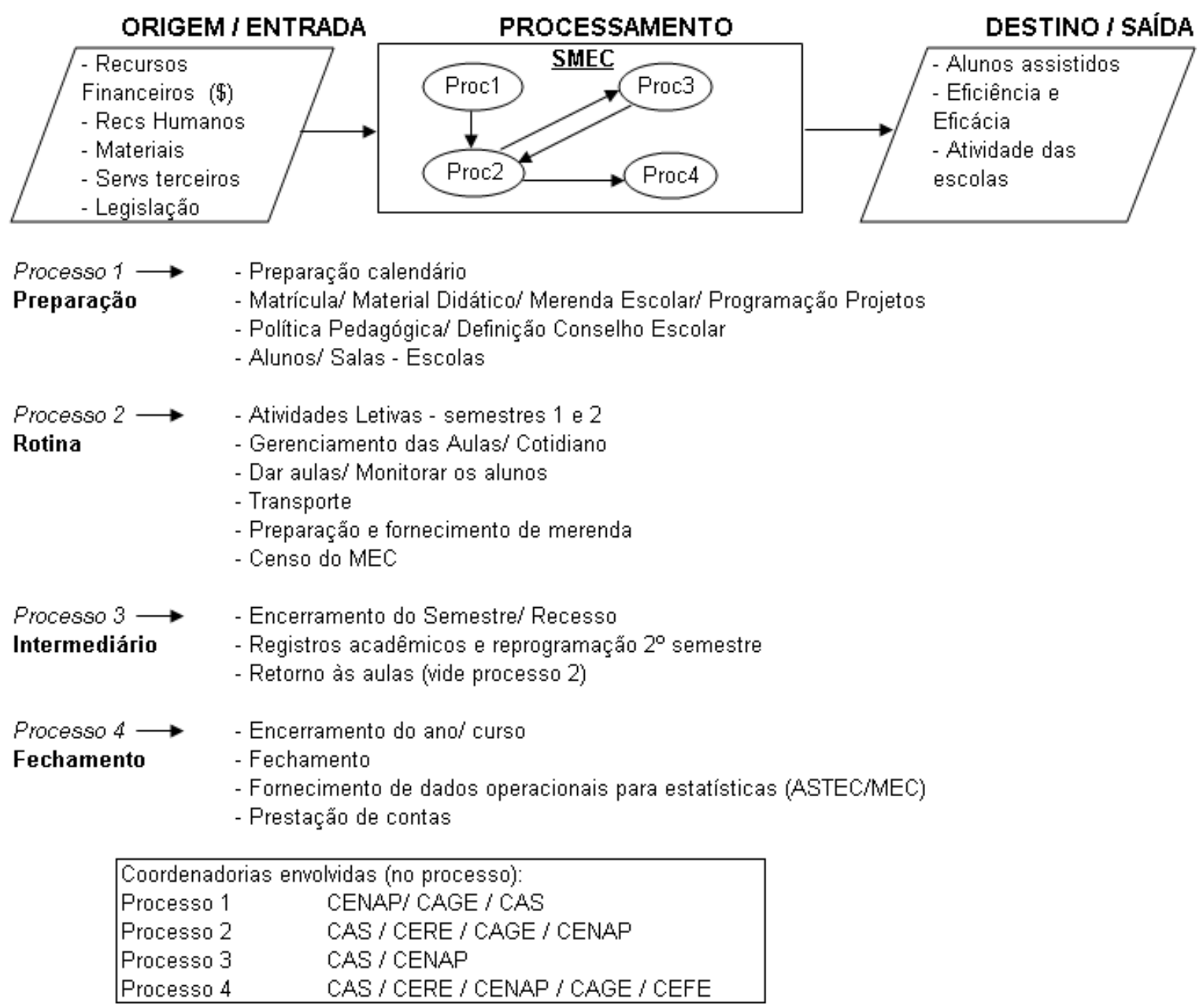

Figura 3 - Macro-fluxo das atividades escolares de uma escola padrão na SMEC/SSA

Mesmo com o sentido auto-explicativo do fluxograma, há que se ressaltar que o processo dois se repete porque se trata de uma rotina seguida nos dois semestres. Ao final do primeiro semestre ocorre um processo intermediário, iniciando-se logo após o segundo semestre. Por essa razão, num segundo momento, passa-se do processo dois para o processo quatro que é de encerramento e balanço geral do ano com as estatísticas e prestação de contas.

Além do objetivo de se verificar como funcionavam as escolas, o levantamento buscou também identificar relacionamentos de causa e efeito entre as coordenadorias e as escolas e relacioná-las aos projetos e atividades constantes dos instrumentos de 
planejamento. Além disto, foram levantados com a gestora do FME todos os relatórios e informes que contivessem informações de uso gerencial, ou seja, interno e administrativo.

Entre os pontos analisados cabe destacar:

- As metas quantitativas contempladas na LDO e PPA que indicam os projetos e atividades para associar com os respectivos valores em $R \$$ contidos na LOA;

- O Plano de Aplicação Bimestral (PAB), como desdobramento da LOA para efeito de controle e aprimoramento do orçamento. Também foram observados os dados reais do PAB, como redirecionadores do que se gastou, o que faltava gastar, o que precisava ser suplementado, compensado ou anulado, entre outros;

- Os projetos/atividades até elemento de despesa, usando o Sistema de Gestão Fiscal (SGF) como fonte das informações de execução orçamentária (função, subfunção, programa, projeto/atividade e elemento de despesa) e como um balizador, para efeito de "consistência", com as informações coletadas nos demais sistemas e subsistemas, que serão abordados em tópico posterior;

- Os indicadores físico-operacionais das diversas unidades, contidos ou não no Sistema de Gestão Educacional (SGE).

Após a definição de quais informações seriam necessárias ao SGC e de quais seriam os objetos de custeio do modelo conceitual, foi realizada uma investigação mais detalhada visando estabelecer critérios lógicos de transferência dos custos dos setores administrativos para os setores finais. Foi nessa etapa que se concentrou a "inteligência" do SGC, ou seja, o modus operandi do sistema. De forma seqüencial, as informações identificadas foram:

- Coletadas nos diversos sistemas e subsistemas de informações; 
- Verificadas com os totais registrados nos sistemas de origem, promovendo a consistência simultânea ou final com os dados da execução orçamentária no SGF;

- Combinadas, adaptadas, compatibilizadas e direcionadas, de acordo com a sua directibilidade, para os diversos objetos de custeio parciais e finais;

- Atribuídas aos objetos de custeio finais da SMEC como custos diretos e indiretos quais sejam: custo por escola/ mês e ano, custo por aluno/ mês e ano, custo por segmento de ensino/ mês e ano, custo por programa/projeto/atividade / mês e ano.

Os sistemas e subsistemas utilizados e o seu relacionamento com o SGC estão representados de forma esquemática na Figura 4, mais adiante. A seguir constam as características sumárias de alguns desses sistemas:

- SGF - Sistema de Gestão Fiscal: é o sistema contábil da SMEC; contempla ainda todos os contratos e convênios realizados pela Secretaria, além de servir como controle orçamentário financeiro;

- SGE - Sistema de Gestão Escolar: compreende informações relativas a quantidade de alunos e professores por escola, por serie, por turma e turno entre outros;

- SGRH - Sistema de Gestão de Recursos Humanos: contempla informações sobre os salários dos funcionários e professores, além dos encargos sociais recolhidos pela Prefeitura. É gerido pela SEAD (Secretaria Municipal de Administração);

- SIMAT - Sistema de Materiais: contempla todos os materiais de consumo, expediente e limpeza usados em toda a Secretaria. É gerido também pela SEAD;

- Sistemas Periféricos: Controle de almoxarifado administrado pela $C A D$, pois o SIMAT ainda não havia sido totalmente implantado nesta Secretaria. 


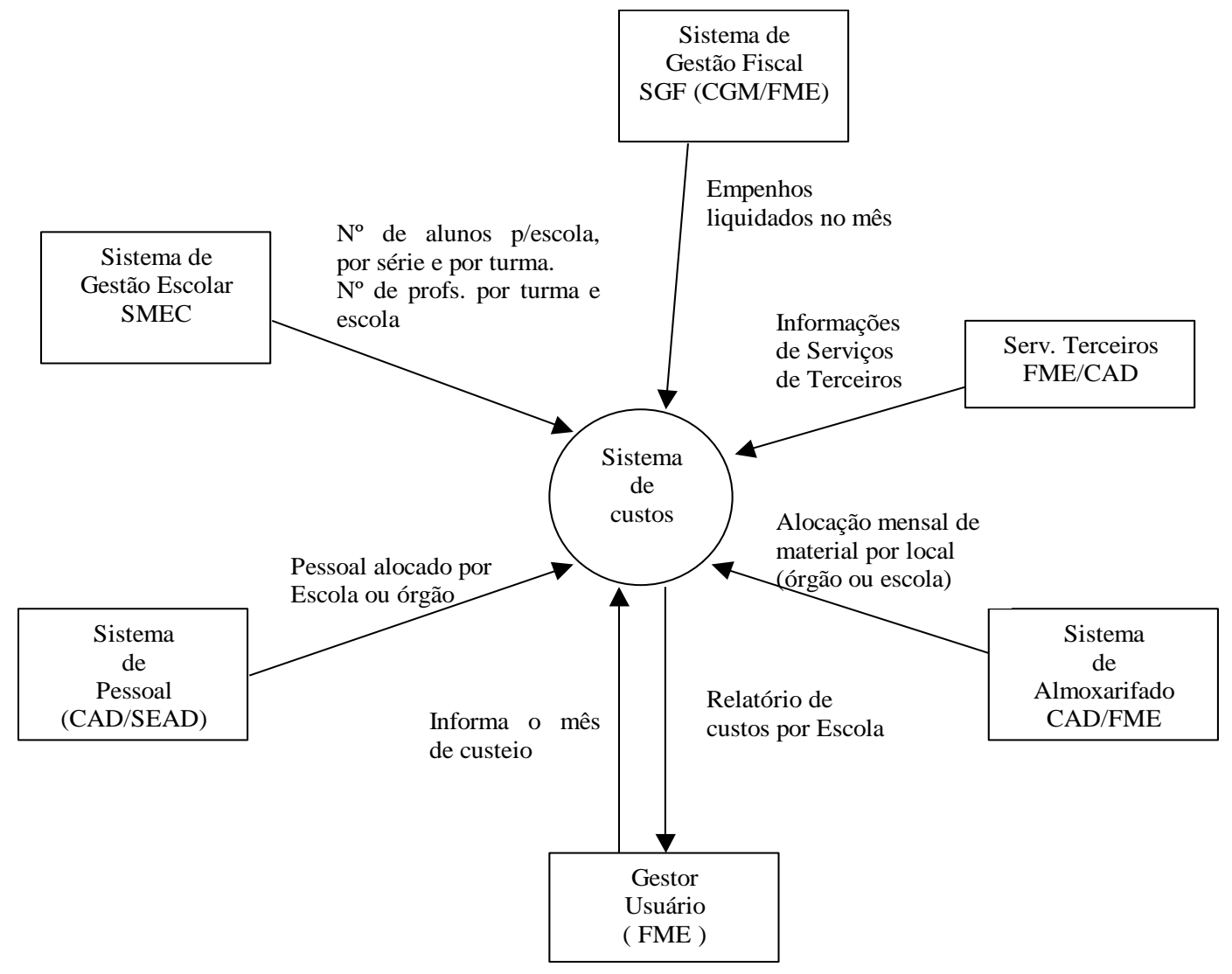

Figura 4 - Informações básicas necessárias ao SGC da SMEC/SSA

\subsection{Fundamentação teórico-doutrinária utilizada}

$\mathrm{Na}$ fase inicial de implantação do SGC na SMEC, o método de custeio adotado foi o de absorção, o qual considera a apropriação de todos os custos (diretos e indiretos ou fixos e variáveis) do período, aos objetos finais de custeio, no caso as escolas e os alunos. Além da razão para adoção deste método estar justificada no Quadro 2, foi definido pelos gestores da SMEC que era fundamental determinar o custo acumulado de cada escola e o custo acumulado por aluno, em cada escola de cada região administrativa.

Conforme informações descritas no referencial teórico, geralmente seria muito arriscado adotar uma sistemática de custos trabalhosa e onerosa como o $\mathrm{ABC}$ numa fase inicial de implantação. Durante o projeto conceitual, foi admitido utilizar o $A B C$ 
numa etapa posterior (a médio e longo prazo), principalmente pelo argumento de que no setor de serviços, são os processos e atividades é que são geridos e não o serviço final em si, que seria uma conseqüência, ou seja, o resultado do processo ou atividade.

O sistema de acumulação de custos adotado foi o de custeio por processo contínuo em função dos processos e atividades acontecerem de forma permanente e pelo fato de que geralmente um ente público tem como fonte de sua receita principal uma dotação orçamentária do que é arrecadado a nível federal, estadual e municipal.

Quanto à classificação dos custos, foi adotado o critério de custos diretos e indiretos, principalmente em função de se mensurar os objetos de custeio e não o volume dos objetos de custeio. Exemplo: custos diretos e indiretos da Escola, do segmento de ensino $5^{a}$ a $8^{\text {a }}$ séries entre outros. O método de acumulação e distribuição de custos até os objetos de custeio finais (Custo por Escola e Custo por Aluno) foi o de Departamentalização, conforme já justificado no referencial teórico. A partir da constância da observação, do controle da sistemática implantada e da formação de massa crítica, outros métodos mais adequados e refinados poderão ser inseridos sem prejuízo do esforço inicial.

Outro detalhe relevante diz respeito à depreciação, a qual não foi incluída nos custos de forma oficial, ou seja, oriunda do sistema contábil. As razões para isto se assemelham às de qualquer outra entidade do setor público, ou seja: não havia (e ainda não há) um sistema de controle patrimonial atualizado na contabilidade; as taxas de depreciação utilizadas têm um caráter muito mais fiscal do que econômico, razão pela qual poderia não representar adequadamente o patrimônio da entidade pública. Outro aspecto é que na estrutura da SMEC (administração e escolas) os bens de maior valor agregado são os imóveis. As instalações e móveis e utensílios não são suntuosos, não existem laboratório de informática em todas as escolas e existem poucos veículos de uso restrito da secretaria.

Desse modo foi feito um cálculo estimado de depreciação apenas para finalidade gerencial, chegando-se a um custo aproximado de $R \$ 4,20$ por aluno. Neste cálculo considerou-se todo o conjunto do imobilizado a custos correntes, usando-se as taxas de depreciação condizentes com as espécies de bens do imobilizado. O objetivo desse 
cálculo é tão somente permitir a comparação dos custos da SMEC (custo por escola e custo por aluno) com os custos por aluno do setor privado, em especial, de escolas mais populares.

\subsection{Custos apurados pelo modelo}

Os gastos constantes nas tabelas apresentadas a seguir, referem-se às Atividades da SMEC do mês de março, conforme mencionado. Os gastos relativos aos Projetos não foram considerados no estudo por se tratarem ou de aumento patrimonial ou de programas pontuais que geram benefícios por vários exercícios. Na Tabela 1 podem ser vistos os Custos da Estrutura Administrativa e Operacional da SMEC, sem as Coordenadorias Regionais e as Escolas. Esses custos serão transferidos mais adiante, pelos critérios de número de alunos por coordenadoria regional e número de alunos por escola, para as respectivas escolas para determinação dos custos totais por escola e por aluno.

Tabela 1: Custo mensal por centros de custos administrativos - Em $R \$ 1,00$

\begin{tabular}{l|r|r|r|r|r|r}
\hline \multirow{2}{*}{ Elementos de custos } & \multicolumn{6}{|c}{ CENTROS DE CUSTOS ADMINISTRATIVOS (CCA) } \\
\cline { 2 - 7 } & \multicolumn{1}{|c|}{ ADM } & \multicolumn{1}{c}{ CERE } & \multicolumn{1}{c}{ CAGE } & \multicolumn{1}{c}{ CENAP } & \multicolumn{1}{c}{ CAS } & \multicolumn{1}{c}{ TOTAL } \\
\hline Pessoal e encargos & 266.000 & 61.230 & 52.030 & 100.620 & 120.740 & 600.620 \\
\hline Materiais de consumo & 5.250 & 83 & 8.133 & 8.133 & 83 & 21.682 \\
\hline Serviços de Terceiros - PJ & 65.260 & 2.640 & 44.200 & 63.710 & 7.370 & 183.180 \\
\hline Serviços Terceiros - Outros & 16.330 & & 6.864 & 19.874 & & 43.068 \\
\hline Outros gastos & 22.340 & 390 & 21.600 & 21.600 & 11.412 & 77.342 \\
\hline \hline \multicolumn{1}{c|}{ Total geral } & 375.180 & 64.343 & 132.827 & 213.937 & 139.605 & 925.892 \\
\hline
\end{tabular}

Na Tabela 2 pode ser visto o total dos custos da SMEC do mês de março de 2002, separados por centros de custos administrativos (CCA), centros de custos intermediários $(\mathrm{CCl})$, os quais representam as CRE's e os centros de custos finais (CCF). 
Gestão de Custos no Setor Governamental: Experiência numa Secretaria Municipal de Educação

Tabela 2: Custo mensal por centros de custos globais - Em $R \$ 1,00$

\begin{tabular}{l|r|r|r|r}
\hline \multirow{2}{*}{ Elementos de custos } & \multicolumn{1}{c|}{ CCA's } & \multicolumn{1}{c|}{ CCI's } & \multicolumn{1}{c|}{ CCF's } & \multirow{2}{*}{ TOTAL } \\
\cline { 2 - 4 } & \multicolumn{1}{c|}{ ADM } & \multicolumn{1}{c|}{ CRE's } & \multicolumn{1}{c|}{ Escolas } & \\
\hline Pessoal e encargos & & & & \\
\hline Materiais de consumo & 21.682 & 70.050 & 259.440 & 351.172 \\
\hline Serviços de Terceiros - PJ & 183.180 & 179.340 & 2.026 .720 & 2.389 .240 \\
\hline Serviços Terceiros - Outros & 43.068 & 47.830 & 17.230 & 108.128 \\
\hline Outros gastos & 77.342 & 89.670 & 10.650 & 177.662 \\
\hline \multicolumn{1}{c|}{ Total geral } & 925.892 & 984.700 & 5.335 .420 & 7.246 .012 \\
\hline \hline CC: Centros de custos & A - Administrativos; I - Intermediários; F - Finais
\end{tabular}

Numa primeira análise dos dados, pode-se perceber que além do custeio de pessoal, o custeio com serviços de terceiros é bastante elevado; os dois juntos representaram $91 \%$ do total dos custos. A maior parte do valor de serviços de terceiros concentra-se nas escolas.

Dentro dos gastos com pessoal foram incluídas as provisões de remunerações e encargos sociais incidentes compatíveis com os parâmetros do regimento único do servidor. Esse foi um ponto significativo no estudo em se tratando da relevância destes gastos.

$\mathrm{Na}$ Tabela 3 pode ser vista a abertura dos custos das Coordenadorias Regionais (CRE's) pelas regiões abrangidas no estudo, no caso o Centro, São Caetano e Orla.

Tabela 3: Custo mensal segundo as CRE's - Em $R \$ 1,00$

\begin{tabular}{l|r|r|r|r|r}
\hline \multicolumn{1}{c|}{ DESCRIÇÅ0 } & Centro & S. Caetano & \multicolumn{1}{c|}{ Orla } & \multicolumn{1}{c|}{ Demais } & \multicolumn{1}{c}{ TOTAL } \\
\hline Pessoal e encargos & 66.070 & 61.540 & 57.570 & 412.630 & 597.810 \\
\hline Materiais de consumo & 5.100 & 7.200 & 8.300 & 49.450 & 70.050 \\
\hline Serviços de Terceiros - PJ & 19.820 & 24.620 & 15.540 & 119.360 & 179.340 \\
\hline Serviços de Terceiros - Outros & 5.940 & 5.540 & 5.180 & 31.170 & 47.830 \\
\hline Outros gastos & 8.590 & 8.000 & 7.480 & 65.600 & 89.670 \\
\hline \multicolumn{1}{c|}{ Total geral } & 105.520 & 106.900 & 94.070 & 678.210 & 984.700 \\
\hline
\end{tabular}

$\mathrm{Na}$ Tabela 4 estão apresentados os dados físicos e operacionais relativos às escolas adotadas como amostra no estudo. Através destes dados foi possível determinar os custos por aluno e servir de indicação para posterior avaliação dos custos por segmento de ensino. 
Gestão de Custos no Setor Governamental: Experiência numa Secretaria Municipal de Educação

Antonio Lopo Martinez

Tabela 4: Dados físicos operacionais das Escolas contempladas no estudo

\begin{tabular}{|c|c|c|c|c|c|c|}
\hline \multirow[t]{2}{*}{ DESCRIÇÃO } & \multicolumn{2}{|c|}{$\begin{array}{l}\text { CRE Centro } \\
\text { A. Rodrigues }\end{array}$} & \multicolumn{2}{|c|}{$\begin{array}{c}\text { CRE S. Caetano } \\
\text { H. Magalhães }\end{array}$} & \multicolumn{2}{|c|}{$\frac{\text { CRE Orla }}{\text { T. Sampaio }}$} \\
\hline & Unids & $N^{\circ}$ alunos & Unids & $N^{\circ}$ alunos & Unids & $N^{\circ}$ alunos \\
\hline Número de professores & 31 & & 35 & & 64 & \\
\hline Turmas: Total & 24 & 536 & 36 & 1.028 & 50 & 1.456 \\
\hline - Pré-escola & 2 & 45 & - & - & - & - \\
\hline - Series 1 a 4 & 6 & 172 & 15 & 386 & 21 & 550 \\
\hline - Séries 5 a 8 & 9 & 202 & 20 & 627 & 27 & 835 \\
\hline - Supletivo & 4 & 57 & - & - & - & - \\
\hline - Telecurso & 3 & 60 & 1 & 15 & 2 & 71 \\
\hline
\end{tabular}

$\mathrm{Na}$ tabela 5, observa-se que para fazer a transferência foi utilizado o total de alunos existentes na rede pública municipal, ou seja, 117.840 alunos distribuídos em cada CRE. Dessa forma os custos transferidos para as CRE's do Centro, São Caetano e Orla foram respectivamente $R \$ 74.147,00$ para 9.440 alunos, $R \$ 105.895,00$ para 13.482 alunos e $\mathrm{R} \$ 72.647,00$ para 9.249 alunos.

Tabela 5: Transferência dos custos mensais da administração para as regiões - Em $R \$ 1,00$

\begin{tabular}{|c|c|c|c|c|c|}
\hline DESCRIÇÃO & Centro & S. Caetano & Orla & Demais & TOTAL \\
\hline CCA para CRE's & & & & & \\
\hline Quantidade de alunos por CRE & 9.440 & 13.482 & 9.249 & 85.709 & 117.880 \\
\hline Gastos administrativos & & & & & 925.892 \\
\hline Total por aluno & & & & & 7,85 \\
\hline Custos distribuídos & 74.147 & 105.895 & 72.647 & 673.204 & 925.892 \\
\hline
\end{tabular}

Na Tabela 6 são determinados os valores a serem transferidos para as escolas, através dos custos acumulados por aluno de cada região administrativa. Dessa forma as escolas da CRE do Centro, com 9.440 alunos, receberão custos indiretos de R \$19,03 por aluno; as escolas da CRE de São Caetano, com 13.482 alunos, receberão de custos de $R \$ 15,78$ por aluno e as escolas da CRE da Orla receberão $R \$ 18,03$ por aluno. 
Gestão de Custos no Setor Governamental: Experiência numa Secretaria Municipal de Educação

Antonio Lopo Martinez

Tabela 6: Acumulação mensal dos custos adm. com os custos das regiões - Em $R \$ 1,00$

\begin{tabular}{l|r|r|r|r|r}
\hline \multicolumn{1}{c|}{ DESCRIÇÄ0 } & \multicolumn{1}{c|}{ Centro } & S. Caetano & \multicolumn{1}{c|}{ Orla } & \multicolumn{1}{c}{ Demais } & \multicolumn{1}{c}{ TOTAL } \\
\hline Gastos das CRE's & 105.520 & 106.900 & 94.070 & 678.210 & 984.700 \\
\hline Gastos transfs dos CCA's & 74.147 & 105.895 & 72.647 & 673.204 & 925.892 \\
\hline \hline Sub-total gastos acumulados & 179.667 & 212.795 & 166.717 & 1.351 .414 & 1.910 .592 \\
\hline \hline Quantidade de alunos por CRE's & 9.440 & 13.482 & 9.249 & 85.709 & 117.880 \\
\hline Custo por aluno (CCA e CRE) & 19,03 & 15,78 & 18,03 & 15,77 & 16,21 \\
\hline
\end{tabular}

Os totais determinados na Tabela 7 são transferidos para a Tabela 8, a seguir, que finalmente, tem o objetivo de mostrar os custos totais das escolas, distribuídos em custos diretos e indiretos e por elemento de despesa.

Tabela 7: Custos mensais totais transferidos para as escolas - Em $\mathrm{R} \$ 1,00$

\begin{tabular}{|c|c|c|c|c|c|}
\hline DESCRIÇÃO & A. Rodrigues & H. Magalhães & T. Sampaio & Demais & TOTAL \\
\hline CCA's e CRE's para Escolas & & & & & \\
\hline Quantidade de alunos por escola & 536 & 1.028 & 1.456 & 114.860 & 117.880 \\
\hline$x$ Custo por aluno (CCA + CRE) & 19,03 & 15,78 & 18,03 & & \\
\hline = Custos distribuídos & 10.201 & 16.226 & 26.245 & 1.857 .920 & 1.910 .592 \\
\hline
\end{tabular}

As informações contidas na Tabela 8 representam, portanto, o conjunto de todos os custos acumulados da estrutura da SMEC (CCA, CCI e CCF) apropriados para estas três escolas. São estes dados que, uma vez apurados sistematicamente, irão fornecer as condições necessárias para permitir a análise e o controle para a tomada de decisões.

Observa-se que os custos totais das escolas representam de $66 \%$ a $70 \%$ dos valores totais, cabendo cerca de $30 \%$ a $34 \%$ relativos aos custos que vieram transferidos dos setores estruturais. Seria um indicador bom? Serão estes custos por aluno altos ou baixos? Através destas informações, a SMEC poderá, entre outras coisas, promover análises comparativas com o setor privado, auxiliar no processo orçamentário, contribuir na gestão identificando oportunidades de otimização da eficiência e da economicidade. 
Numa comparação simples, suponha que a mensalidade de uma escola particular popular da classe média tenha preços em torno de $R \$ 130,00$ a $R \$ 170,00$. Tomando o parâmetro médio, $\mathrm{R} \$ 150,00$ mensais, estimando uma carga tributária de $10 \%$ e uma margem para cobrir lucro e encargos administrativos de $30 \%$ por dentro, chega-se ao valor de custo por aluno de $\mathrm{R} \$ 94,50$. Os custos por aluno da SMEC, com base nesta amostra, situam-se entre $R \$ 50,00$ a $R \$ 60,00$. Tomando o valor mais alto de $R \$ 57,64$ e somando os $R \$ 4,20$ de depreciação, chega-se a um custo de $R \$ 61,84$, ou seja, cerca de $R \$ 62,00$ por aluno, o que representa uma variação de $34,4 \%$ a menos que o custo da escola particular em referência.

Tabela 8: SMEC - Custos mensais totais por escola e por aluno - Em $R \$ 1,00$

\begin{tabular}{|c|c|c|c|c|c|c|}
\hline \multirow{2}{*}{ DESCRIÇÃO } & Centro & Perc & S. Caetano & Perc & Orla & Perc \\
\hline & A. Rodrigues & $(\%)$ & H. Magalhães & (\%) & T. Sampaio & $(\%)$ \\
\hline Quantidade de alunos & 536 & $\mathrm{~A} / \mathrm{V}$ & 1.028 & $\mathrm{~A} / \mathrm{V}$ & 1.456 & $\mathrm{~A} / \mathrm{V}$ \\
\hline \multicolumn{7}{|l|}{ Custos Diretos (CD) } \\
\hline Pessoal e encargos & 13.677 & $45,6 \%$ & 28.511 & $54,9 \%$ & 48.267 & $57,5 \%$ \\
\hline Materiais didático/expediente & 290 & $1,0 \%$ & 608 & $1,2 \%$ & 861 & $1,0 \%$ \\
\hline Merenda escolar & 1.470 & $4,9 \%$ & 2.182 & $4,2 \%$ & 3.193 & $3,8 \%$ \\
\hline Outros gastos & 29 & $0,1 \%$ & 16 & $0,0 \%$ & 24 & $0,0 \%$ \\
\hline Sub-total (CD) & 15.466 & $51,5 \%$ & 31.317 & $60,3 \%$ & 52.345 & $62,4 \%$ \\
\hline \multicolumn{7}{|l|}{ Custos Indiretos (Cl) } \\
\hline Pessoal e encargos & 3.672 & $12,2 \%$ & 3.852 & $7,4 \%$ & 4.326 & $5,2 \%$ \\
\hline Materiais de consumo & 58 & $0,2 \%$ & 70 & $0,1 \%$ & 80 & $0,1 \%$ \\
\hline Serviços de Terceiros - PJ & 352 & $1,2 \%$ & 400 & $0,8 \%$ & 531 & $0,6 \%$ \\
\hline Serviços de Terceiros - Outros & 261 & $0,9 \%$ & & $0,0 \%$ & 321 & $0,4 \%$ \\
\hline Outros gastos & & $0,0 \%$ & 100 & $0,2 \%$ & 79 & $0,1 \%$ \\
\hline Sub-total (Cl) & 4.343 & $14,5 \%$ & 4.422 & $8,5 \%$ & 5.337 & $6,4 \%$ \\
\hline Sub-total da Escola & 19.809 & $66,0 \%$ & 35.739 & $68,8 \%$ & 57.682 & $68,7 \%$ \\
\hline Custos indiretos transferidos & 10.201 & $34,0 \%$ & 16.226 & $31,2 \%$ & 26.245 & $31,3 \%$ \\
\hline Total geral por escola & 30.010 & $100 \%$ & 51.965 & $100 \%$ & 83.927 & $100 \%$ \\
\hline Custo total por aluno (mensal) & 56,00 & 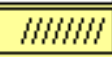 & 50,55 & $\mid / / / / / / 1$ & 57,64 & /I///W/ \\
\hline
\end{tabular}

\section{CONCLUSÕES}

O trabalho apresenta um caso real de implantação de um sistema de acumulação de custos desenvolvido in loco na Secretaria Municipal de Educação de 
Salvador - SMEC. A despeito de limitações de ordem técnica e política, foram identificadas motivações para que os entes públicos busquem implantar um sistema de custos. Entre estas estão: a) o dever de prestar contas (accountability) de maneira transparente e objetiva à sociedade; e b) a pressão pela profissionalização da gestão pública. Adicionalmente, discutiu-se de forma abrangente os principais benefícios de um sistema de custos no setor público, destacando-se: i) a melhoria do processo de planejamento; ii) o aproveitamento ou redução da capacidade ociosa e iii) o controle da economicidade das operações.

A análise comparativa entre as metodologias de custos indicou que no curto prazo o mais apropriado é o custeio por absorção com departamentalização e, no médio a longo prazo, o custeio baseado em atividades representa um ideal a ser atingido.

Após a caracterização organizacional e operacional da SMEC é apresentado um modelo conceitual, estruturado desde o seu diagnóstico inicial, incorporando um plano de intervenção e os resultados apurados com base em levantamento de dados in loco. Uma vez identificados os objetivos norteadores, foi realizada uma investigação minuciosa nos dados da contabilidade e nos dados operacionais de cerca de 360 escolas. Para efeito de exposição didática da metodologia foram apurados os custos para três escolas desse universo.

Com base na estrutura organizacional e nos principais processos e atividades, o modelo foi desenvolvido buscando relacionar os principais projetos e atividades constantes da Lei Orçamentária Anual e execução orçamentária e identificar critérios de relacionamento para transferir e carregar os custos dos setores administrativos e intermediários para os objetos de custeio finais, definidos na fase preliminar que foram as escolas e os alunos.

$\mathrm{Na}$ apresentação das tabelas com os valores do levantamento de campo, mostra-se toda a sequência de operações que culminam com a determinação dos custos acumulados de toda a estrutura da SMEC por escola e por aluno. Os custos por aluno ficaram entre $R \$ 50,00$ a $R \$ 58,00$ e os custos por escola foram de $R \$ 30.010,00$ para 536 alunos; $\mathrm{R} \$ 51.965,00$ para 1.028 alunos e $\mathrm{R} \$ 83.927,00$ para 1.456 alunos. 
A título de exemplo foi comparado o custo por aluno médio da amostra com o custo referência de uma escola privada popular, custo esse deduzido de sua mensalidade em torno de $\mathrm{R} \$ 150,00$, chegando a um custo de $\mathrm{R} \$ 94,50$. Adicionando-se $\mathrm{R} \$ 4,20$ referentes ao custo de depreciação estimado para a SMEC por aluno, tem-se um custo de $R \$ 61,84$ para a rede municipal e $R \$ 94,50$ para a referida escola privada, indicando que a escolas municipais têm um custo inferior em $34,4 \%$ aos custos de escolas privadas de porte sócio-econômico similar.

Estas observações, à guisa de conclusão, servem como provocação para que mais experiências sejam trazidas à baila para análise, discussão e aperfeiçoamento dos propósitos e dos meios profissionais e acadêmicos para se desenvolver soluções para a implantação de sistemas de custos no setor público. A sociedade está ansiosa por novos tempos em que a chamada "nova gestão pública" se constitua num objetivo permanente da administração pública, onde os fantasmas da corrupção, dos desvios de erário público e dos desperdícios sejam minimizados e concentrados nos fins a que eles se propõem.

\section{REFERÊNCIAS}

BRASIL. (2001). Lei de responsabilidade fiscal: lei complementar $n .0101$, de 4-5-2000. Colaboração de Antonio Luiz de Toledo Pinto, Márcia Cristina Vaz dos Santos Windt e Luiz Eduardo Alves de Siqueira. (2 ed.). São Paulo: Saraiva. 64 p. (Saraiva de Legislação).

COSTA, Magnus Amaral da. (1998). Custo-Padrão: sempre atual como tecnologia contábil da informação. Revista do CCSA/UFRN, Natal, RN.

MARTINS, Eliseu. (2003). Contabilidade de Custos. (9 ed.). São Paulo: Atlas.

MEIRELLES, H.L. (2006). Direito Administrativo Brasileiro. (35 ed.). São Paulo: Malheiros Editores.

ROEHL-ANDERSON J; BRAGG S. (2008). Controllership, The Work of the Managerial Accountant, John Willey \& Sons, $\left(8^{\text {th }}\right)$. Edition. 
SILVA, Lino Martins da. (1996). Contribuição ao estudo para implantação de sistema de custeamento na administração pública. 203f. (Tese de Livre Docência). Universidade Gama Filho - Rio de Janeiro.

SLOMSKI, Valmor. (2009). Manual de contabilidade pública: um enfoque na contabilidade municipal, de acordo com a lei de responsabilidade fiscal. (2 ed.). São Paulo: Atlas.

Data de Submissão: 01/03/2010

Data de Aceite: 14/12/2010 